\title{
Pancreatic Mucinous Noncystic (Colloid) Carcinomas and Intraductal Papillary Mucinous Carcinomas Are Usually Microsatellite Stable
}

Jutta Lüttges, M.D., Kurt Beyser, Ph.D., Susanne Pust, Anja Paulus, Josef Rüschoff, M.D., Günter Klöppel, M.D.

Department of Pathology, University of Kiel (JL, SP, AP, GK), and Department of Pathology, General Hospital Kassel (KB, JR), Germany

Pancreatic mucinous noncystic (colloid) carcinomas (MNCC) differ from the usual ductal adenocarcinomas in their mucin expression profile and share with many extrapancreatic mucinous carcinomas the expression of MUC2. Because mucinous carcinomas are frequently associated with mutations of the DNA mismatch repair genes, causing them to exhibit the so-called mutator phenotype, we decided to investigate whether MNCCs of the pancreas are characterized by microsatellite instability (MSI). Twelve carcinomas with a mucinous phenotype (8 mucinous noncystic carcinomas, 3 intraductal papillary-mucinous carcinomas with an invasive muconodular component, and 1 ductal adenocarcinoma with an extensive mucinous noncystic component) and 11 ductal adenocarcinomas were immunostained with monoclonal antibodies to the mismatch repair gene products hMLH1, hMSH2, and hMSH6. For MSI analysis, DNA was isolated from microdissected tissue, and five primary microsatellites (BAT 25, BAT 26, D5S346, D17S250, and D2S123) were analyzed. MSI was diagnosed in case a novel allele was found, compared with the normal tissue. The criterion for $\mathrm{LOH}$ was a $75 \%$ signal reduction. All carcinomas tested exhibited nuclear expression of mismatch repair gene products, except for one MNCC that also showed MSI at the molecular level. The data suggest that pancreatic carcinomas with a mucinous phenotype (MUC2+/MUC1-) do not appear to normally exhibit mutations in the

Copyright ( $(2003$ by The United States and Canadian Academy of Pathology, Inc.

VOL. 16, NO. 6, P. 537, 2003 Printed in the U.S.A

Date of acceptance: March 10, 2003.

Supported by grants from the Deutsche Krebshilfe and the IZKF, Christian-Albrechts-Universität Kiel.

This work includes parts of the doctoral thesis of Susanne Pust.

Address reprint requests to: Jutta Lüttges, M.D., Department of Pathology,

University of Kiel, Michaelisstr. 11, 24105 Kiel, Germany; fax: +49 431597

3462; e-mail: jluettges@path.uni-kiel.de.

DOI: 10.1097/01.MP.0000072748.65178.2F mismatch repair genes and therefore differ in their carcinogenesis from those in other organs.

KEY WORDS: DNA mismatch repair genes, Mucinous phenotype, Pancreatic carcinoma.

Mod Pathol 2003;16(6):537-542

The WHO classification lists mucinous noncystic (colloid) carcinomas (MNCC) of the pancreas as a variant of ductal adenocarcinoma (DAC). Recently, MNCCs were characterized on the basis of their clinicopathological features and their mucin expression profile $(1,2)$. The prognosis of MNCCs is better than that of DACs (1). Most, if not all, MNCCs seem to derive from Type 1 intraductal papillarymucinous neoplasms (IPMN), which are characterized by the expression of MUC2 only, a villous arrangement of the dark, columnar tumor cells, and, if invasive, a muconodular component (2). Like Type 1 IPMNs, MNCCs are positive for glycoprotein MUC2. This distinguishes them from the MUC1-positive DACs. MNCCs also seem to differ from DACs in their lower frequencies of K-ras or p53 mutations (1). The carcinogenesis of DACs has been shown to comprise a stepwise accumulation of molecular alterations (2-4). Thus DACs seem to follow the tumor suppressor pathway (5) or the multistep model, according to Fearon and Vogelstein $(6,7)$, that applies to the majority of carcinomas. Exceptions to the rule are carcinomas showing a mucinous phenotype (8). They frequently follow a different pathway, exhibiting microsatellite instability (MSI) and the so-called mutator phenotype (9). MSI results from mutations of the mismatch repair (MMR) genes (hMLH1, hMSH2, hMSH6, hPMS1, and hPMS2) (10). It is characterized by an expansion or reduction within short tandem repeats (11). MSI and mutations of the MMR genes are the genetic background of the hereditary nonpolyposis colon carcinoma syndrome (HNPCC; 11-13). The HNPCC-associated co- 
lon carcinomas frequently reveal a distinct morphology, in that they are of a medullary or mucinous phenotype $(14,15)$. Both types of carcinoma, the medullary and the mucinous variant, are rare in the pancreas. The Johns Hopkins group (1618) described a series of 18 medullary type carcinomas, 4 of which had MSI, and 12, wild-type K-ras.

The MSI status of MNCCs and related IPMNs has not yet been determined. The purpose of the present study was therefore to analyze these tumors for the presence of mutations of the MMR genes and for possible MSI.

\section{MATERIALS AND METHODS}

In a series of $>630$ pancreatic carcinomas from the consultation files of one of the authors (GK), 12 carcinomas were found that showed an extensive invasive mucinous component. From these, two to six paraffin blocks were available. Eight carcinomas were of the MNCC type, with a mucinous component comprising $>80 \%$ (including two cases with an extensive signet ring cell component); three were intraductal papillary mucinous carcinomas (IPMCs) showing an invasive muconodular component, and one was a DAC with a mucinous component (comprising $<50 \%$ of the tumor tissue). These carcinomas and 11 DACs were investigated immunohistochemically and by molecular analysis. In three cases, the paraffin blocks were $>18$ years old. In an earlier study investigating the mucin expres- sion profile (2), the MNCCs and IPMCs included in this study showed MUC2 positivity, whereas the DACs were MUC1 positive (Table 1).

\section{Immunostaining}

Three- $\mu$ m-thick sections were cut from at least two representative tissue blocks from each tumor (in three cases, only one block was available). Immunostaining was performed as described elsewhere (2). Briefly, antibodies against the mismatch repair gene protein products, hMLH1 (Clone 14; Oncogene, Boston, MA; dilution, 1:5), hMSH2 (Clone GB 12; Oncogene; dilution, 1:12.5), hMSH2 (Clone FE11; Oncogene; dilution, 1:12.5), and hMSH6 (Clone 44; BD Biosciences, Heidelberg, Germany; dilution, 1:50) were applied using an immunostainer (Ventana NexES ICH, Ventana Medical Systems, Tucson, AZ). To improve the staining sensitivity, a 3,3'-diaminobenzidine-enhanced detection kit (Ventana) and an amplification kit (Ventana) were employed. The staining intensity was additionally enhanced using the Envision system (DAKO, Hamburg, Germany). Antibody detection was performed by adding biotinylated secondary antibodies, avidin-biotin complex, and 3,3'-diaminobenzidine. The three cases with old tissue blocks were only partially stainable, even after repeated and prolonged demasking of the antigen by pressure cooking. The various components of the IPMCs, i.e., borderline tumor, intraductal carcinoma, and invasive carcinoma, were evaluated separately. Tumor-free adja-

TABLE 1. Clinicopathological Features, Immunoprofiles, and Microsatellite Instability (MSI) of Mucinous Noncystic Carcinomas (MNCCs), Intraductal Papillary Mucinous Carcinomas (IPMCs), and Ductal Adenocarcinomas (DACs) of the Pancreas

\begin{tabular}{|c|c|c|c|c|c|c|}
\hline Case & Diagnosis & Age & Stage & $\begin{array}{c}\text { MUC } \\
\text { Immunoprofile }\end{array}$ & $\begin{array}{c}\text { MMRP } \\
\text { Immunoprofile }\end{array}$ & MSI \\
\hline 1 & MNCC & 56 & $\mathrm{~T} 2 \mathrm{~N} 1$ & MUC2+ & $+^{*}$ & - \\
\hline 2 & MNCC & 62 & $\mathrm{~T} 2 \mathrm{~N} 1$ & MUC2+ & + & - \\
\hline 3 & MNCC & 73 & T1N1 & MUC2+ & - & + \\
\hline 4 & MNCC & 74 & T2N0 & MUC2+ & + & - \\
\hline 5 & MNCC & 75 & T3Nx & MUC2+ & $+^{*}$ & - \\
\hline 6 & MNCC & 39 & T3Nx & MUC2+ & + & - \\
\hline 7 & MNCC & 80 & T3N1 & MUC2+ & + & B. \\
\hline 8 & MNCC & 11 & T4M1 & MUC2(+) & ${ }^{* *}$ & - \\
\hline 9 & IPMC & 77 & T1N0 & MUC2 & + & - \\
\hline 10 & IPMC & 77 & $\mathrm{~T} 1$ & MUC2+ & + & - \\
\hline 11 & IPMC & 58 & $\mathrm{~T} 4$ & MUC2+ & + & - \\
\hline 12 & $\mathrm{DAC}^{* * *}$ & 71 & T3N1 & MUC1+ & + & - \\
\hline 13 & DAC & 61 & T3N1 & MUC1+ & + & - \\
\hline 14 & DAC & 63 & T3N1b & MUC1+ & + & - \\
\hline 15 & DAC & 81 & T3N1 & MUC1+ & + & - \\
\hline 16 & DAC & 70 & T4N1 & MUC1+ & + & - \\
\hline 17 & DAC & 53 & T3N1 & MUC1+ & + & - \\
\hline 18 & DAC & 66 & T3N1 & MUC1+ & + & - \\
\hline 19 & DAC & 65 & T2N0 & MUC1+ & + & - \\
\hline 20 & DAC & 72 & T3N1 & MUC1+ & + & - \\
\hline 21 & DAC & 45 & T3N0 & MUC1+ & + & - \\
\hline 22 & DAC & 53 & T3N0 & MUC1+ & + & - \\
\hline 23 & DAC & 65 & T3N1b & MUC1+ & + & - \\
\hline
\end{tabular}

MMRP = mismatch repair gene products hMLH1, hMSH2 and hMSH6; ${ }^{*}$ MLH 1 not stainable; ${ }^{* *}$ no immunostaining possible; *** DAC with mucinous component staining weakly for MUC2; B. = Bouin fixation; + = strong cytoplasmic staining, or nuclear staining; $(+)=$ weak cytoplasmic staining of a few cells. 
cent pancreatic parenchyma and tissue from colon carcinomas served as controls.

\section{Microdissection}

From the tumor blocks, a representative $10-\mu \mathrm{m}$ thick section was cut, and the tumor was microdissected by needle scraping or by laser dissection (Arcturus MWG, Munich, Germany). Approximately $1 \mathrm{~cm}^{2}$ of tumor tissue was digested with proteinase $\mathrm{K}$ buffer at $48^{\circ} \mathrm{C}$ for 12 hours and then purified. PCR was performed by the multiplex PCR method (Boehringer Mannheim, Germany) or by using single primers with fluorescence-labeled markers (19). In Case 8, a rare case of carcinoma in a child (an 11-year-old Japanese boy), only H\&E-stained slides were available. The slides were uncovered, and the tissue was microdissected. It yielded well-preserved DNA for the analysis.

\section{Molecular Analysis}

For the MSI analysis, a recommended marker panel (20) was used: BAT25, BAT26, D2S346, D17S250, and D2S123. The amplified PCR product was analyzed on an ABI PRISM 310 automated sequencer (Applied Biosystems, Weiterstadt, Germany). MSI was defined as the presence of novel alleles that were not present in the normal DNA.

\section{RESULTS}

\section{Immunohistochemistry}

Twenty-one tumors were stained immunohistochemically. In one case (Case 8), no slides were available for immunostaining. With the exception of Case 3, all tumors, including the intraductal and the invasive muconodular component of the IPMCs, the MNCCs, and the DACs, revealed intense nuclear reactivity for hMSH2 and hMSH6 (Fig. 1, Table 1). In some cases with extensive mucus extravasation, the staining appeared to be weaker or even negative. However, this finding was restricted to a few cell groups (and was possibly caused by incomplete antigen demasking within the mucus). Nuclear immunoreactivity for hMLH1 was found in all but three cases (Cases 1, 3, and 5). Whereas in Case 3 normal tissue showed nuclear reactivity, both other cases were completely negative even after prolonged antigen demasking ( $c f$. above). In these two cases, the failure to stain for hMLH1 was most probably caused by antigen degradation, because these tissue blocks were $>18$ years old.

\section{Molecular Analysis}

Using a microdissection technique, intraductal and invasive components of the IPMCs were ana-

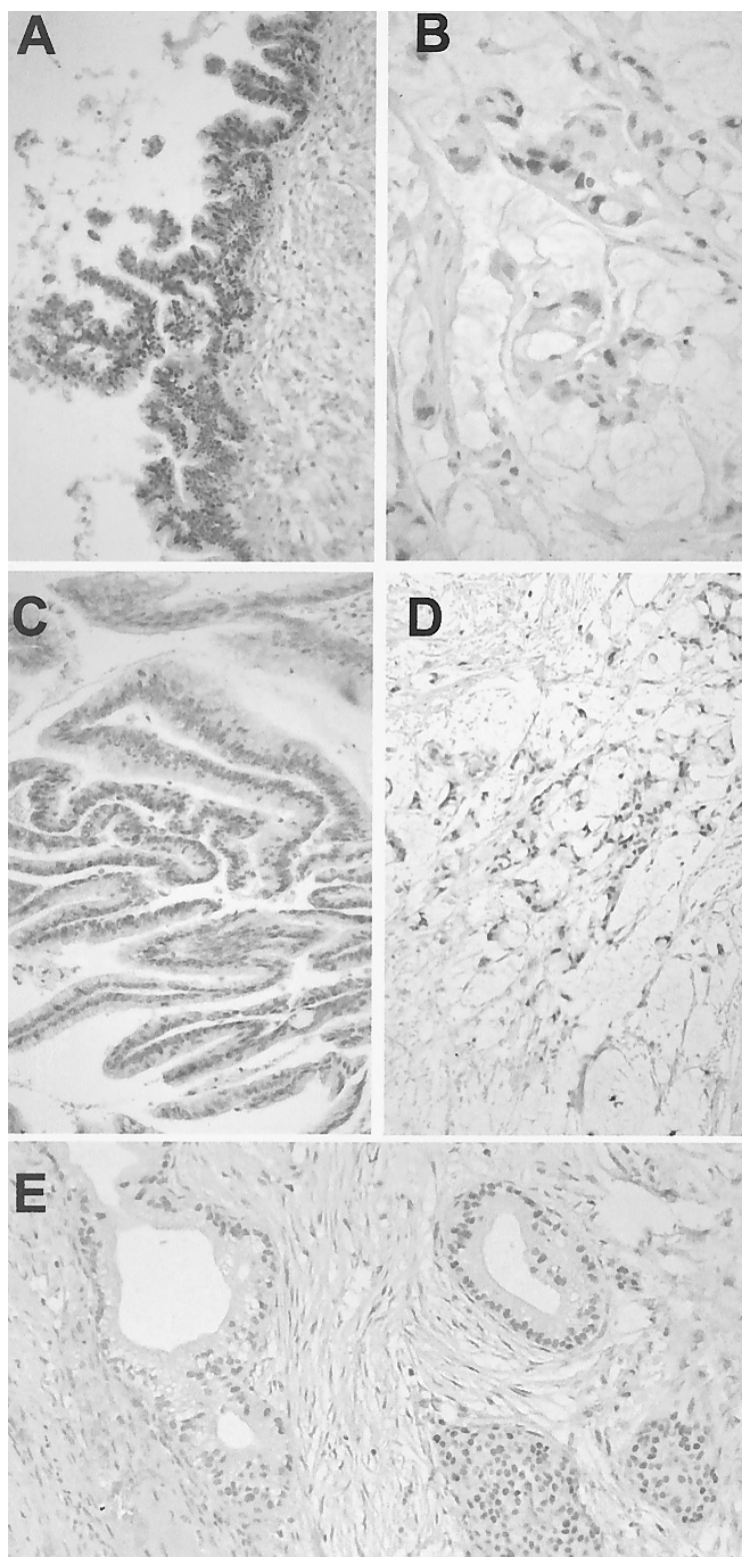

FIGURE 1. A, intraductal component of an invasive mucinous noncystic carcinoma: nuclear hMHS1 protein expression. B, invasive mucinous noncystic carcinoma: nuclear hMSH1 expression. C, intraductal papillary mucinous borderline neoplasm (IPMB) with hMLH2 positivity. D, invasive muconodular component of IPMC, hMLH2 positive. E, invasive ductal adenocarcinoma with nuclear hMSH6 expression

lyzed separately, as were the mucinous and nonmucinous components of DACs. After prolonged digestion with proteinase $\mathrm{K}$ and repeated purification, all cases were amplifiable except for one (Case 7 ), for which only Bouin-fixed material was available ( $c f$. Table 1). Microsatellite stability was found in all analyzed specimens, except for Case 3, i.e., 7 MNCCs; 3 IPMCs, including their muconodular component; the 1 DAC with a mucinous component; and all other DACs (Table 1, Fig. 2). One MNCC (Case 3) showed MSI for all applied markers (Fig. 3) and thus was considered MSI high (20). This carcinoma did not reveal either a signet ring cell 


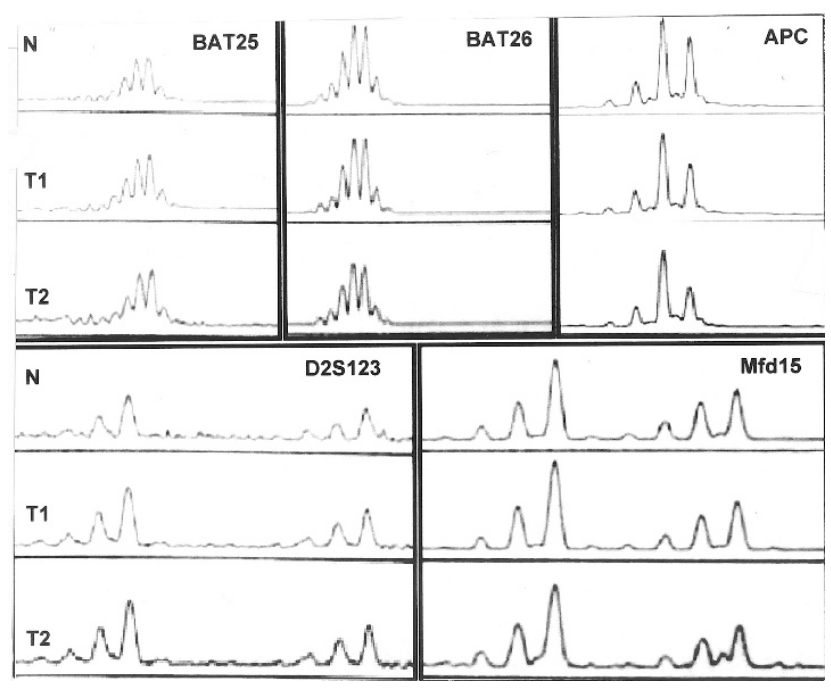

FIGURE 2. Microsatellite analysis of Case 6: mucinous noncystic carcinoma, normal tissue, intraductal component $(\mathrm{T})$, and invasive component (T2); no MSI for any markers.

component or other morphological features that distinguished it from the other cases. It was located in the head of the pancreas and measured $8 \mathrm{~cm}$ in diameter. On histological slides from four blocks, the carcinoma exhibited a mucinous component, comprising $>80 \%$ without a medullary component. The major tumor mass was located in the head of the pancreas and extended to the ampulla. There was a minimal intraductal component extending to the resection margin. Intraductal growth in at least a few interlobular segments was also a feature of the other MNCCs but not to such an extent as to classify them as IPMNs. No data were available on tumor recurrence or overall survival in Case 3.

\section{DISCUSSION}

Mutations of the mismatch repair genes lead to microsatellite instability. They have been found to cause the HNPCC syndrome but have also been detected in sporadic carcinomas $(14,21)$. Frequently, the MSI carcinomas are of a special histological type, such as medullary carcinomas (15) or, more often, mucinous carcinomas (22). The tissue of the latter carcinomas is composed of $>50 \%$ mucin-producing tumor cells and mucus extravasation. In various organs such as the ovary, colon, breast, or stomach, mucinous carcinomas are characterized by the expression of the MUC2 glycoprotein $(8,23)$.

In the pancreas, mutations of the MMR genes have been described in four cases of medullary carcinoma $(16,17)$, all but one of which showed wild-type K-ras. Usual adenocarcinomas of the pancreas did not reveal MSI (17). The MSI status of

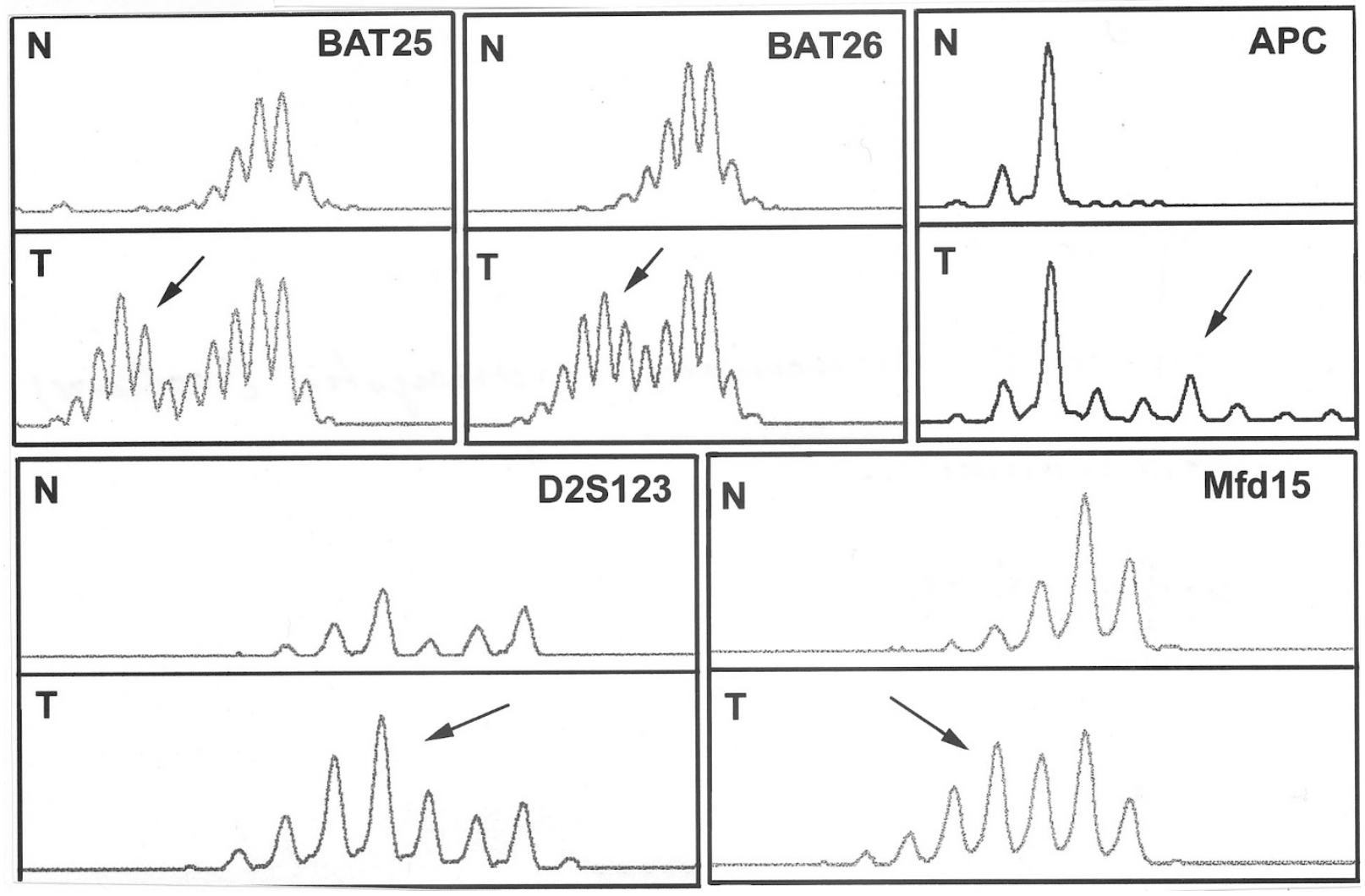

FIGURE 3. Microsatellite analysis of Case 3: mucinous noncystic carcinoma and normal tissue showing MSI for all markers (additional peaks marked by arrows). 
mucinous carcinomas in the pancreas, which are called MNCCs (24) or colloid carcinomas (1), has not yet been fully analyzed. MNCCs are rare in the pancreas, accounting for only $0.1 \%$ in our series of 412 primary exocrine carcinomas (data not shown). Recently, it was found that most MNCCs derive from IPMCs with an invasive muconodular component and express MUC2 instead of MUC1 $(1,2,25)$. These findings clearly showed that MNCCs are distinct from the MUC1-positive DACs. Moreover, Adsay et al. (1) found K-ras mutations in only 4 of 12 and p53 mutations in 2 of 9 MNCCs, a frequency that is much lower than that found in DACs $(26,27)$. As a further feature of the genetic profile of MNCCs, and contrary to what was expected, we can now add that only one of the MNCCs and none of the MUC2positive IPMCs (including their invasive muconodular component) that we tested revealed MSI. The one MSI-positive MNCC (Case 3) showed both lack of nuclear expression of the MMR gene products and MSI for all markers (and thus was MSI high). The intraductal carcinoma component in the cases that we classified as MNCCs was too small to allow them to be clearly classified as IPMN, although the MUC2 phenotype suggests such a histogenesis. Histologically, Case 3 was indistinguishable from the MSI-negative MNCCs. In particular, there was no medullary component, and the major mass of the tumor was located in the head of the pancreas. Because the DACs of our series and those of other studies (17) also lack MSI, mutations of the MMR genes appear to be the exception in pancreatic tumors. Immunostaining with a panel of antibodies proved to be a reliable screening method for detecting MMR gene defects, because there were no false-negative results in our series. Immunohistochemical screening for MSI is well established in colorectal carcinomas (28). However, one has to pay particular attention to antigen demasking for hMLH1, which seems to be more critical than that for hMSH2 and hMSH6.

It has been suggested that the mucinous phenotype, i.e., carcinomas consisting of $>50 \%$ mucus or mucus-producing cells, follows a second pathway of carcinogenesis that is distinct from the stepwise accumulation of genetic alterations that is seen in most other carcinoma types. In the ovary, the colorectum, and breast, the mucinous phenotype was shown to express the glycoprotein MUC2, but not MUC1 $(8,29)$. In their study on colorectal carcinomas, Biemer-Hüttmann et al. (30) found a strong association between MSI and mucinous tumors positive for MUC2 and MUC5AC, supporting the hypothesis of a special pathway of carcinogenesis for mucinous carcinomas in general $(8,31)$. However, the data from our study indicate that this concept does not apply to the pancreas.
In summary, it appears that MUC2-positive mucinous tumors of the pancreas are exceptions among the group of mucinous carcinomas because of their usually MSI-negative genotype. This distinction is further substantiated by the fact that these pancreatic neoplasms have not yet been found to be associated with the HNPCC syndrome that, in other organs, commonly involves carcinomas of the mucinous type (31).

Acknowledgments: The authors thank Maike Pacena for her excellent technical assistance and Katherine Dege for editing the manuscript.

\section{REFERENCES}

1. Adsay NV, Pierson C, Sarkar F, Abrams J, Weaver D, Conlon $\mathrm{KC}$, et al. Colloid (mucinous noncystic) carcinoma of the pancreas. Am J Surg Pathol 2001;25:26-42.

2. Lüttges J, Zamboni G, Longnecker D, Klöppel G. The immunohistochemical mucin expression pattern distinguishes different types of intraductal papillary mucinous neoplasms of the pancreas and determines their relationship to mucinous noncystic carcinoma and ductal adenocarcinoma. Am J Surg Pathol 2001;25:942-8.

3. Heinmöller E, Dietmaier W, Zirngibl H, Heinmöller P, Scaringe $\mathrm{W}$, Jauch $\mathrm{KW}$, et al. Molecular analysis of microdissected tumors and preneoplastic intraductal lesions in pancreatic carcinoma. Am J Pathol 2000;157:83-92.

4. Yamano M, Fujii H, Takagaki T, Kadowaki N, Watanabe H, Shirai T. Genetic progression and divergence in pancreatic carcinoma. Am J Pathol 2000;156:2123-33.

5. Rozenblum E, Schutte M, Goggins M, Hahn SA, Panzer S, Zuhurak M, et al. Tumor-suppressive pathways in pancreatic carcinoma. Cancer Res 1997;57:1731-4.

6. Fearon ER, Vogelstein B. A genetic model for colorectal tumorigenesis. Cell 1990;61:759-67.

7. Vogelstein B, Fearon ER, Hamilton SR, Kern SE, Preisinger AC, Leppert M, et al. Genetic alterations during colorectaltumor development. N Engl J Med 1988;319:525-32.

8. Hanski C, Hofmeier M, Schmitt-Gräff A, Riede E, Hanski ML, Borchard F, et al. Overexpression or ectopic expression of MUC2 is the common property of mucinous carcinomas of the colon, pancreas, breast, and ovary. J Pathol 1997;182: 385-91.

9. Loeb LA. Cancer cells exhibit a mutator phenotype. Adv Cancer Res 1998;72:25-56.

10. Lynch HT, Smyrk T. Hereditary nonpolyposis colorectal cancer (Lynch syndrome). An updated review. Cancer 1996;78: 1149-67.

11. Aaltonen LA, Peltomaki P, Leach FS, Sistonen P, Pylkkanen L, Mecklin JP, et al. Clues to the pathogenesis of familial colorectal cancer. Science 1993;260:812-6.

12. Lynch HT, Smyrk TC, Watson P, Lanspa SJ, Lynch JF, Lynch $\mathrm{PM}$, et al. Genetics, natural history, tumor spectrum, and pathology of hereditary nonpolyposis colorectal cancer: an updated review. Gastroenterology 1993;104:1535-49.

13. Thibodeau SN, Bren G, Schaid D. Microsatellite instability in cancer of the proximal colon. Science 1993;260:816-9.

14. Jass JR, Do KA, Simms LA, Iino H, Wynter C, Pillay SP, et al. Morphology of sporadic colorectal cancer with DNA replication errors. Gut 1998;42:673-9.

15. Rüschoff J, Dietmaier W, Lüttges J, Seitz G, Bocker T, Zirngibl $\mathrm{H}$, et al. Poorly differentiated colonic adenocarcinoma, medullary type. Clinical, phenotypic, and molecular characteristics. Am J Pathol 1997;150:1815-25. 
16. Goggins M, Offerhaus GJ, Hilgers W, Griffin CA, Shekher M, Tang D, et al. Pancreatic adenocarcinomas with DNA replication errors (RER + ) are associated with wild-type K-ras and characteristic histopathology. Poor differentiation, a syncytial growth pattern, and pushing borders suggest RER + . Am J Pathol 1998;152:1501-7.

17. Wilentz RE, Goggins M, Redston M, Marcus VA, Adsay NV, Sohn TA, et al. Genetic, immunohistochemical, and clinical features of medullary carcinoma of the pancreas: a newly described and characterized entity. Am J Pathol 2000;156:1641-51.

18. Wilentz RE, Geradts J, Maynard R, Offerhaus GJ, Kang M, Goggins $\mathrm{M}$, et al. Inactivation of the p16 (INK4A) tumorsuppressor gene in pancreatic duct lesions: loss of intranuclear expression. Cancer Res 1998;58:4740-4.

19. Dietmaier W, Gänsbauer S, Beyser K, Renke B, Hartmann A, Rümmele $\mathrm{P}$, et al. Microsatellite instability in tumor and nonneoplastic colorectal cells from hereditary nonpolyposis colorectal cancer and sporadic high microsatelliteinstable tumor patients. Pathobiology 2000;68:227-31.

20. Boland CR, Thibodeau SN, Hamilton SR, Sidransky D, Eshleman JR, Burt RW, et al. A National Cancer Institute Workshop on Microsatellite Instability for cancer detection and familial predisposition: development of international criteria for the determination of microsatellite instability in colorectal cancer. Cancer Res 1998;58:5248-57.

21. Messerini L, Vitelli F, de Vitis LR, Mori S, Calzolari A, Palmirotta $\mathrm{R}$, et al. Microsatellite instability in sporadic mucinous colorectal carcinomas: relationship to clinico-pathological variables. J Pathol 1997;182:380-4.

22. Jass JR. Diagnosis of hereditary non-polyposis colorectal cancer. Histopathology 1998;32:491-7.

23. Gürbüz Y, Kahlke V, Klöppel G. How do gastric carcinoma classification systems relate to mucin expression patterns?
An immunohistochemical analysis in a series of advanced gastric carcinomas. Virchows Arch 2002;440:505-11.

24. Klöppel G, Hruban RH, Longnecker DS, Adler G, Kern SE, Partanen TJ. Ductal adenocarcinoma of the pancreas. In: Hamilton SR, Aaltonen LA, editors. Pathology and genetics of tumours of the digestive system. WHO classification of tumours. Lyon, France: IARC Press; 2000. p. 221-30.

25. Seidel G, Zahurak M, Iacobuzio-Donahue CA, Sohn TA, Adsay NV, Yeo CJ, et al. Almost all infiltrating colloid carcinomas of the pancreas and periampullary region arise from in situ papillary neoplasms. A study of 39 cases. Am J Surg Pathol 2002;26:56-63.

26. Almoguera C, Shibata D, Forrester K, Martin J, Arnheim N, Perucho M. Most human carcinomas of the exocrine pancreas contain mutant c-K-ras genes. Cell 1988;53:549-54.

27. Scarpa A, Capelli P, Mukai K, Zamboni G, Oda T, Iacono C, et al. Pancreatic adenocarcinomas frequently show p53 gene mutations. Am J Pathol 1993;142:1534-43.

28. Chaves P, Cruz C, Lage P, Claro I, Cravo M, Leitão CN, et al. Immunohistochemical detection of mismatch repair gene proteins as a useful tool for the identification of colorectal carcinoma with the mutator phenotype. J Pathol 2000;191:355-60.

29. Dong Y, Walsh MD, Cummings MC, Wright RG, Khoo SK, Parsons PG, et al. Expression of MUCland MUC2 mucins in epithelial ovarian tumours. J Pathol 1997;183:311-7.

30. Biemer-Hüttmann AE, Walsh MD, McGuckin MA, Simms LA, Young J, Leggett BA, et al. Mucin core protein expression in colorectal cancers with high levels of microsatellite instability indicates a novel pathway of morphogenesis. Clin Cancer Res 2000;6:1909-16.

31. Jass JR. Mucin core proteins as differentiation markers in the gastrointestinal tract. Histopathology 2000;37:561-4. 